\title{
ESTUDIOS
}

\section{Consideraciones antropológicas sobre identidad y tradición, a partir del documento episcopal Las raíces cristianas de Cataluña (1985)'}

\section{Lluís Duch ${ }^{2}$}

Resumen: En fechas recientes el episcopado catalán ha publicado un documento titulado "Al servicio de nuestro pueblo" en el que subraya la vigencia del documento de 1985 "Las raíces cristianas de Cataluña». Con ocasión de los veinticinco años de éste, el autor reflexiona desde un punto de vista antropológico sobre el concepto de "identidad" y su relación con los de "cultura" $y$ "tradición", con la finalidad de poner de manifiesto algunas posibilidades y límites del texto episcopal.

Palabras clave: Cultura, identidad, nación, tradición.

Fecha de recepción: 21 de febrero de 2011 .

\footnotetext{
' El original de este estudio apareció en catalán en Qüestions de vida cristiana n 238 (201 1) 29-42, con el título "Les arrels cristianes de Catalunya", en un monográfico que, en su conjunto, estaba dedicado a comentar, recordar y valorar el documento del año 1985 de la Conferencia episcopal tarraconense "Las raíces cristianas de Cataluña". Posteriormente, el 17 de marzo de 2011, el episcopado catalán ha publicado un documento titulado "Al servicio de nuestro pueblo" en el que subraya la vigencia del documento de 1985. El artículo original del prof. Duch debe entenderse dentro del contexto del mencionado monográfico conmemorativo. El original catalán apareció sin notas a pie de página que aquí se incorporan por iniciativa del autor. La traducción del original es de JMM, de la redacción de Revista de Fomento Social. El original fue recibido, previa solicitud, el 21-II-2011.

2 Profesor de Antropología, Universidad Autónoma de Barcelona. Monasterio de Montserrat.
} 


\section{Anthropological considerations on identity and tradition, from the episcopal document Christian roots in Catalonia (1985)}

Abstract: Recently Catalan Bishops have published a document entitled "Serving our people" which stresses the validity of the 1985 paper" Christian Roots in Catalonia." On the occasion of its twenty-fifth anniversary of publication, the author reflects on the concept of "identity" and its relation to "culture" and "tradition" from an anthropological standpoint in order to highlight some of the possibilities and limitations found in this episcopal text.

Key words: Culture, identity, nation, tradition.

\section{Considérations anthropologiques sur l'identité et la tradition, à partir du document épiscopal "Les raci- nes chrétiennes de la Catalogne» (1985)}

Résumé: L'épiscopat catalan a récemment publié un document intitulé "Au service de notre peuple», dans lequel il met en avant la vigueur du document publié en 1985 «Les racines chrétiennes de la Catalogne». À l'occasion de son $25^{\text {ème }}$ anniversaire, I' auteur fait une réflexion du point devue anthropologique sur le concept «d'identité» et sa relation avec ceux de "culture» et «tradition», dans le but de mettre en évidence quelques possibilités et limitations du texte épiscopal.

Mots-clé: Culture, identité, nation, tradition.

Desde una perspectiva pastoral, no hay duda de que en el documento sobre «Las raíces cristianas de Cataluña» los obispos catalanes ofrecieron una aproximación al hecho catalán que apenas se había abordado en la historia de nuestro país. ${ }^{3}$ Considerar el peso específico de la tradición cristiana en la historia y el desarrollo de Cataluña con toda la seriedad posible es algo que debe despertar un profundo respeto y reconocimiento en todas las personas que se interesan por la actualidad del mensaje cristiano en Cataluña y por el futuro social y político de la nación catalana. Para bien y para mal, la historia, los marcos jurídicos, culturales y sociales, el imaginario colectivo, la literatura, el calendario, la toponimia y un largo etcétera son fenómenos completamente inexplicables sin la presencia y la influencia de la religión cristiana desde los mismos comienzos históricos de una entidad concreta y con personalidad propia llamada Cataluña. Negar este hecho significaría con-

${ }^{3}$ Puede verse la aproximación crítica que hice en su momento y que con algunos retoques mantuve en L. Duch (2010) Religió i comunicació, Barcelona, Fragmenta, 328-341. 
denarse a no comprender nada de nada de lo ocurrido en este pequeño territorio del Mediterráneo occidental desde los primeros siglos de la era cristiana.

Al menos desde un punto de vista antropológico, el documento episcopal que, como ya hemos dicho, posee un indudable carácter pastoral con rasgos muy significativos y relevantes, nos parece que debe ser considerado y calibrado con otros parámetros. De esta manera, creemos, será posible evitar algunas confusiones que, en un tiempo de crisis generalizada como el nuestro, pueden tener unas consecuencias no muy deseables e incluso francamente anticristianas, como la historia de nuestro país desgraciadamente ha puesto de relieve con frecuencia.

Para evitar las posiciones esencialistas, tan peligrosas y tan frecuentes al mismo tiempo en relación con esta problemática, queremos referirnos muy brevemente a una cuestión que suele determinar decisivamente, sobre todo en momentos de confusión social, religiosa y política como son los actuales, las tomas de posición de un gran número de personas y de grupos humanos. Nos referimos a la problemática, siempre vidriosa y extremadamente conflictiva y que, además, nunca es inocente, en torno a la identidad, que, como es ampliamente reconocido, se encuentra estrechamente emparentada con la de las raíces, hasta tal punto que, muy frecuentemente, pueden ser considerados como dos términos casi sinónimos. Justamente en los momentos de desconcierto y desorientación generales es cuando, de una manera más o menos explícita, se suele plantear la problemática en torno a la identidad; a menudo, hay que decirlo todo, con unos intereses no muy recomendables. Esto resulta muy comprensible porque precisamente en estos momentos de confusión y vacilación, el interrogante "¿quién soy yo?" o "¿quiénes somos nosotros?" posee a nivel individual y colectivo una urgencia mucho mayor y plantea unos desafíos que suelen ser desconocidos en los tiempos y las situaciones marcados por una cierta normalidad en la vida cotidiana de los individuos y de las colectividades.

Como escribe Robert N. Bellah, creemos que la gente vive a través de historias. La identidad personal no tiene sino una estructura narrativa. Esto equivale a decir que el establecimiento y la consolidación de la presencia en el mundo, que son propias de individuos y colectividades, coinciden con la identidad que ellos mismos se atribuyen en un proceso narrativo, que, como sucede con todos los procesos narrativos, sea en los textos sagrados de las religiones, sea en los cuentos populares, se encuentran sometidos a cambios constantes 0 , mejor aún, a imparables contextualizaciones y adaptaciones. No debería olvidarse, sin embargo, que la identidad es un fenómeno que surge de la dialéctica entre el individuo y la sociedad y que sirve al individuo y a los grupos humanos para dar respuestas con 
indudables rasgos biográficos a los interrogantes explícitos o implícitos que nunca dejan de plantearse: "¿quién soy yo?", "quiénes somos nosotros?"

Reduciéndola a casos extremos -una especie de aplicación de la teoría de los «tipos ideales» de Max Weber a esta cuestión-, la problemática en torno a la identidad ofrece dos tipos de solución que son irreconciliables entre sí. La primera hace de la identidad religiosa, cultural, social y política una entidad definitivamente configurada "a priori", una especie de sustancia esencial, anterior a las determinaciones y las peripecias históricas y completamente independiente de ellas, un especie de principio ideal regulador incuestionable y que al mismo tiempo no se puede fundamentar, que es anterior, pero determinante, a todas las tomas de posición que individuos y grupos humanos deben adoptar a lo largo de sus peripecias históricas. Entonces resulta que, con más o menos beligerancia, la identidad se interpreta como si fuera una entidad esencial, con rasgos claramente providenciales, preexistente a la existencia histórica concreta de las personas y de las comunidades humanas. Expresándolo de otro modo: a partir de una concepción esencialista de la identidad se pone gravemente en cuestión la naturaleza histórica del ser humano y de los grupos humanos, lo que equivale a decir que se elimina -o, al menos, se daña profundamente- su presencia en el mundo, en su mundo cotidiano, como seres éticos, aunque muy a menudo, a partir justamente de la comprensión esencialista de la identidad, se les reduzca -o, al menos, se pretenda reducirlos- a ser unos seres simplemente morales. Este modo de entender la identidad incide poderosa $y$, desde nuestra perspectiva, muy negativamente tanto en el ámbito religioso como en el político concretándose todo por regla general de una manera muy explosiva, intransigente y con toques más o menos racistas, en unas determinadas interpretaciones de lo religioso-político, que, de una manera u otra, manifiesta actitudes nostálgicas por el antiguo régimen y sus concepciones sacropolíticas. ${ }^{4}$ En el momento presente, desde puntos de vista muy diversos, y a menudo contrapuestos, este aspecto de la problemática ha adquirido una enorme importancia. ${ }^{5}$ No entraremos en la exposición aunque seamos de la opinión que constituye uno de los lugares más adecuados para captar la situación real de lo

${ }^{4}$ Cfr., L. DucH (2010) «El religiosopolític avui», in Creences, religions i esfera pública: una reflexió per al segle XXI. VI Jornada Ernest Lluch, Vilassar de Mar (Barcelona), Fundació Ernest Lluch, 11-26.

${ }^{5}$ Por citar sólo algunas contribuciones actuales especialmente significativas, cfr. R. MAtE editor (2006) Nuevas teologías políticas. Pablo de Tarso en la construcción de Occidente, Barcelona, Anthropos; M. SCATtOLA (2007) Teologia politica, Bolonia, II Mulino; P. VALADIER (2007) Détresse du politique, force du religieux, París, Seuil; A. FERRARA, editor (2009) Religione e politica nella società post-secolare, Roma, Meltemi; G. Filoramo (2009) II sacro e il potere. Il caso cristiano, Turín, Einaudi; y M. Lilla, El Dios que no nació. Religión, política y el Occidente moderno, Barcelona, Debate. 
religioso y de lo político en el momento actual, junto con sus inevitables relaciones, sean éstas de oposición, alianza o indiferencia según los casos.

Un segundo modelo de identidad, que se desprende del tipo de antropología que aplicamos a nuestra reflexión, mantiene que la problemática en torno a la identidad de una forma directa, o bien oblicuamente, es siempre, individual y colectivamente, inevitable e ineliminable, a pesar de todo lo que se pueda decir en sentido contrario. La radical diferencia respecto al primer modelo consiste en que no se trata de una problemática de carácter esencialista, sino simplemente histórico. Esta toma de posición tiene un precedente importante que hemos señalado muy a menudo en nuestros escritos: para el ser humano no hay posibilidad extracultural. Exponiéndolo de otra manera: la esencia del hombre histórico, que vive en un aquí y ahora concretos, es su cultura concreta. ${ }^{6} Y$ toda cultura es una construcción histórica con todas las peripecias implicadas en cualquier periplo histórico. Aunque, a veces, no seamos conscientes, no hay duda de que la cultura, nuestra cultura, configura nuestra vida con una intensidad similar a como lo hace la fuerza de la gravedad, que se muestra, siempre y en todo, presente y activa a pesar del mismo ser humano. Arnold Gehlen puso de relieve que la esfera cultural, como una especie de presencia ineludible, era el ámbito natural transformado por el hombre, el nido, por decirlo plásticamente, que el hombre se construía en el mundo. La cultura es naturaleza transformada, perfeccionada, reformada mediante la acción inteligente del ser humano que, siguiendo la imagen propuesta por Gehlen, posee la virtud de componer un «nido» a su medida, revisable, ampliable y corregible de acuerdo con las necesidades y los retos de cada momento histórico. La movilidad incesante de las culturas humanas, de la que la ambigüedad que es inherente a la condición humana como tal constituye un rasgo muy significativo, provoca que no exista un centro reconocido y fijo de la "naturaleza humana», sino que ésta se sitúa incesantemente en un ámbito de relaciones fluctuantes y contradictorias, porque el ser humano, como subrayaba el novelista austriaco Robert Musil, es un ser "sin forma» (gestaltlos), nunca condicionado "a priori" porque siempre se presenta y se representa como respuesta en medio del escenario del gran teatro del mundo. Por ello, este autor, con una gran finura, puede hablar del «teorema de la ausencia de forma» (Theorem der Gestaltlosigkeit) para referirse al hecho de que el hombre, incesantemente, en la siempre creciente variedad de espacios y tiempos, se ve constreñido a "asumir caracteres variables, costumbres, morales,

${ }^{6}$ Cfr. L. Duch (2000) Llums i ombres de la ciutat. Antropologia de la vida cuotidiana, Montserrat, Publicacions de l'Abadia, vol. 3, 104-110, 154-165. 
estilos de vida y el aparato entero de una organización». ${ }^{7}$ En definitiva: se trata de poder vivir libre de la presión que sobre individuos y grupos humanos ejercen las legitimaciones absolutas (O. Marquard).

Actualmente, las grandes cuestiones sobre la identidad suelen remitir a la problemática en torno a la cultura: la crisis de la cultura corre en paralelo con la crisis de la identidad, y ésta, como no podía ser de otra manera, tiene mucho que ver con la crisis de la intimidad. Todas estas crisis, como aspectos diferentes de la misma situación, se encuentran condicionadas por el progresivo debilitamiento del Estado-nación que ha tenido lugar a partir de la finalización de la segunda guerra mundial (1945) y también de la intensa pérdida de confianza en la institución eclesiástica, que en otros tiempos, en nuestro país, fue el principal factor regulador de las conductas individuales y colectivas. De ahí que resulte evidente que la actual problemática en torno a la afirmación identitaria de los individuos sea un problema relativamente moderno que, a nuestro juicio, ahora mismo, tiene mucho que ver con los procesos de «neorromantización» de nuestros días. Cuando la vida social se encontraba fuertemente arraigada y justificada en las relaciones comunitarias, el individuo definía su "status", irreflexivamente, por el lugar y por el rango en el seno de la totalidad social. En cambio, en estas últimas décadas, con la progresiva autonomización de las diversas esferas sociales, los códigos de pertenencia, que antaño habían sido diseñados y dictados por la comunidad y asumidos sin problemas por los individuos, han perdido su antigua validez y poder de legitimación y se han convertido una especie de "espacios intermedios», «porosos», «fronterizos», sometidos a interminables procesos de mestizaje.

A principios del siglo XX, Max Weber fue uno de los primeros que se dio cuenta con mucha claridad de que la identidad, integrada en un cuerpo social (comunidad), tal como se había dado en el pasado, se había fracturado definitivamente por la división del trabajo propia de las sociedades industriales. Weber era consciente de vivir en una época con un sujeto escindido en una pluralidad de fragmentos. Esta nueva situación implica que ha llegado el final de la armonía clásica representada simbólicamente por la unión de los dioses de la belleza, de la bondad y de la verdad. Habría que tener bien presente que, en la sociedad premoderna con reconocidos "tics" medievalizantes, que era la referencia del obispo Torras i Bages, inspirador del texto episcopal, el ámbito de lo familiar era coextensivo con el de

7 De ninguna manera cuestionamos la gran importancia de los «hábitos», por utilizar la terminología de Pierre Bourdieu o de O. Marquard. Cfr. P. Bourdieu (1997) Razones prácticas. Sobre la teoría de la acción, Barcelona, Anagrama, y O. MARQUARD (2006) «Sobre la inevitabilidad de los hábitos», en O. MARQUARD (2006) Felicidad en la infelicidad. Reflexiones filosóficas, Buenos Aires, Kazt, 69-84. 
"lo conocido". Lo extraño, por tanto, comprendía todo lo que religiosa, política y socialmente era desconocido y parecía completamente ajeno a este ámbito. La familia y el lugar de nacimiento son los focos más antiguos de la identidad como nosotros que posee el ser humano particular (Norbert Elias).

En un destacable escrito, Tzvetan Todorov pone de relieve que, en el "antiguo régimen", las personas eran lo que eran de una vez por todas. Salvo poquísimas excepciones, hombres y mujeres mantenían una coincidencia identitaria entre el momento de su nacimiento y el de su fallecimiento. En la modernidad, esta forma de concebir la identidad fue superada por los procesos de democratización, acompañados por una amplia gama de posibilidades de movilidad social y de elección que se han dado en casi todas las sociedades occidentales. De todos modos, debe tenerse muy en cuenta que allí donde se ha querido mantener aquella concepción de la identidad propia del "antiguo régimen" como, por ejemplo, en el nacionalsocialismo, en el "apartheid" de África del Sur y en algunas formas actuales, delirantes y muy peligrosas, de nacionalismo, han hecho acto de presencia todas las consecuencias catastróficas que se siguen de la aplicación de la "gramática de lo inhumano» (G. Steiner) en la concreta vida cotidiana.

Una aproximación democrática a la identidad es aquella que no se limita a considerar lo que, supuestamente, son los individuos por nacimiento (mujeres, judíos, negros, catalanes, blancos, cristianos, musulmanes, etc.), sino lo que van haciendo de sus vidas, aquello que van llegando a ser. Como escribe Todorov,

insistir en la pertenencia de origen más que en el desarrollo personal, contribuirá a la expansión del "orgullo étnico". [...] Esto, sin embargo, equivale a oponerse directamente a los valores democráticos fundamentales.

Nunca debería olvidarse que "vamos siendo», que transformamos nuestras vidas, que pensamos, actuamos, hablamos y sentimos a partir de un punto de partida, de una situación cultural concreta, de un «aquí» que no es ni mejor ni peor, pero que, sin embargo, es irreductible a un "alli», porque lo universal, en el ser humano, es como máximo un "desideratum", nunca una determinación "a priori".

El concepto de identidad humana hace alusión a un proceso. Esto es algo que se olvida fácilmente. De entrada podría parecer que las declaraciones sobre el yo y el nosotros poseen un carácter estático (Norbert Elias).

A menudo se ha afirmado que, desde la propia identidad, los individuos se encontraban habilitados para llevar a cabo el conjunto de clasificaciones y reordenaciones que son necesarias para que, en cada aquí y ahora, sea posible responder a los retos y los interrogantes que son coextensivos al ejercicio histórico 
del oficio de mujer o de hombre. Históricamente, la defensa de la autonomía cultural se ha encontrado estrechamente ligada a la preservación de la identidad colectiva. "Cultura» e "identidad» son conceptos que remiten a una misma realidad, observada desde perspectivas diferentes. No se puede dejar de mencionar que, en términos generales, esta perspectiva generadora de una cultura concreta es convencional, porque no es ni la única ni tampoco la más sobresaliente para la realización de la naturaleza cultural del hombre. Además, esta perspectiva nunca se encuentra consolidada definitivamente, ni se mantiene inmutable, sino que se ve sometida a alteraciones y movimientos constantes, de tal manera que, sin cesar, se produce una ósmosis con las otras identidades grupales y visiones del mundo, mediante la cual integra, rechaza, imita, se enriquece con nuevas representaciones y percepciones. La identidad cultural es una ecuación dinámica en la que se combinan inseparablemente elementos más o menos estables y elementos cambiantes y relativamente imprevisibles (A. Memmi). Actualmente, sabemos muy bien que la distinción entre lo que constituye la propia identidad y lo extraño es algo tan móvil como las mismas observaciones que hacemos. Además, creemos que resulta bastante evidente que lo que es familiar (propio) no es un dato ontológico, apriorístico, sino que se trata de un conjunto de magnitudes históricas que van tomando cuerpo, haciéndose y deshaciéndose, en el transcurso de los trayectos biográficos de individuos y grupos humanos, que, además, puede sernos familiar o conocido desde una determinada perspectiva, y extraño o inquietante, desde otra. Serge Gruzinski llega a afirmar que

es suficiente examinar la historia de cualquier grupo humano para darse cuenta de que, admitiendo que su acondicionamiento de prácticas y de creencias posee algún tipo de autonomía, se parece con todo mucho más al movimiento de una nebulosa en incesante cambio que a un sistema bien definido.

Debido a la movilidad cultural, social y económica de los tiempos modernos es muy comprensible que, a menudo, la identidad moderna aparezca mucho más como el resultado de un «bricolage» de sens (Dubet y Martuccelli), que como un dato monolítico, ajeno a los cambios y los conflictos que, inevitablemente y sin excepción, se hacen presentes en el vivir y convivir humanos. Por eso, sin exagerar lo más mínimo, toda identidad, toda referencia a las raíces es un producto de sucesivos mestizajes religiosos, sociales, culturales. Al mismo tiempo hay que tener en cuenta que, a medida que la determinación de los diversos roles por intervención de las instancias sociales se debilita, la identidad de los individuos $-y$ las pertenencias a que da lugar- se vuelve más incierta, fluctuante y cuestionable, provocando, con cierta frecuencia, a nivel individual y colectivo, diversas disfunciones de tipo psicológico. 
Para mantener la identidad física y psíquica de los individuos, siempre sometida e incluso a menudo degradada por los daños derivados del imparable paso del tiempo, no cuesta demasiado comprobar que el ser humano necesita, al mismo tiempo, permanencias relativas y adaptaciones continuadas. En todos los tiempos, pero, sobre todo, en los tiempos modernos, debido a la sobreaceleración del «tempo» vital y de la incesante complejización de los sistemas y los subsistemas sociales (Luhmann), los grupos humanos se encuentran incesantemente en un estado de autoconstitución (Beiner). Por su parte, los individuos, en una sociedad que ha dejado de ser un «nosotros» en un sentido tradicional para convertirse en una sociedad de individuos (Elias), para bien o para mal llegan a identificarse con la calidad o la falta de calidad de sus relaciones. Dubet y Martuccelli subrayan el hecho de que, en los tiempos modernos, "I'identité est travail sur soi", que, una vez que las instituciones clásicas han perdido la función que antaño tuvieron de asegurar la continuidad en el tiempo y la integración social, impone la creación de una nueva articulación de lo individual y lo social, no siempre fácil de conseguir.

Hoy y siempre, pero sobre todo en las épocas de crisis globales de la sociedad, los individuos menos adaptables al cambio (sin olvidar tampoco los numerosos «intereses creados» de todo tipo que nunca dejan de acompañar a los fenómenos sociales) suelen pretender, a menudo con el uso de la fuerza bruta, "deshacer» el camino que hasta entonces había recorrido una determinada cultura y retornar a los orígenes, a un tiempo anterior a las grandes fragmentaciones impuestas por los intereses culturales, tiempo en que el hombre y el mundo eran de verdad lo que debían ser. No hay duda de que esta manera de ver las cosas, en la que suelen tener una fuerte intervención los sentimientos, equivale a poner en cuestión la condición cultural, histórica y social del ser humano tal como ha sido expresada hasta el momento presente. De todos modos, no puede olvidarse que, a pesar de todo lo que pueda decirse en un sentido contrario, este rechazo de la situación presente se hace por medio de los «artefactos culturales» de los que se dispone, ya que cualquier alternativa ("esencialista» o "pragmática») a la cultura de referencia tan sólo es posible a partir de la propia cultura.

Es del todo evidente que toda cultura responde al hecho de que el hombre nunca puede dejar de ser un ser espacio-temporal o, como señalaba incansablemente Maurice Merleau-Ponty, uno de los antropólogos más interesantes del siglo XX, hombres y mujeres habitamos en un espacio y tiempo antropológicos, es decir, nos encontramos referidos al mundo de nuestro momento histórico; ahora bien, se trata de un tiempo y un espacio que, simultánea e indisolublemente, es interno y externo, interiorizado y físico, reflexivo y activo (sin olvidar los imprescindibles y sin embargo importantísimos matices "sentimentales»), lo que pone de relieve el hecho de que 
todo intento de "extraterritorialización» o de "extratemporalización», en función de una comprensión "esencialista» de la humanidad del hombre, para instituir la crítica de la propia cultura es absolutamente irrealizable. ${ }^{8} \mathrm{El}$ tiempo «nuestro» y el espacio "nuestro», histórico-culturales, nos son tan íntimos, tan implicados en el entramado de nuestra propia existencia que, pese a las declaraciones verbales que podamos hacer, nunca somos capaces de situarnos «fuera» o «al margen» de nuestra propia secuencia espacio-temporal (y, secundariamente, de la de nuestro grupo de pertenencia).

Como conclusión y en relación con la problemática en torno a la cultura y la identidad, queremos señalar que resulta imposible vivir humanamente sin un espacio identificador, intersubjetivo, constitutivo de un sí mismo colectivo, en el que se dé el reconocimiento inmediato de un nosotros orgánico, pero también hay que subrayar con toda la fuerza, que no es nada deseable e, incluso, puede ser extremadamente peligroso, vivir en un entramado social que se limite a ser una corroboración permanente, acrítica, de la propia identidad, de las propias raíces, de la propia historia concebida como una magnitud de carácter intemporal y metafísica, o providencialmente, determinada. En este último caso, los individuos que la habitan se ven constreñidos al exilio en lo colectivo. Después de lo que acabamos de exponer, creemos que puede afirmarse que el sí mismo colectivo no es una entidad metafísica, ni siquiera metafórica. En último término, el problema de la identidad remite a su cultura porque, como hemos afirmado con anterioridad, para el ser humano no hay ningún tipo de posibilidad extracultural. En último término, tal como las entendemos, las cuestiones en torno a la identidad manifiestan que hombres y mujeres habitamos en un mundo que tiene historias y que continuará teniéndolas precisamente en el centro del proceso o trayecto que abarca desde el nacimiento a la muerte. Para lo positivo y para lo negativo, estas historias son preciosas, aunque de ninguna manera absolutas, pues no se encuentran fuera del espacio y del tiempo, ni pertenecen al ámbito de los orígenes tal como éstos han sido interpretados por las antropologías esencialistas. Esta observación nos permite adentrarnos en otro aspecto de la problemática, firmemente vinculada con las raíces y la identidad: la "tradición".

La palabra tradición proviene de dos verbos (tradere y transmittere) que hay que distinguir con cuidado. ${ }^{9}$ El primero se refiere a una cosa dada o un objeto entre-

${ }^{8}$ Cfr G. LE BlANC (2005) L'esprit des sciences humaines, París, J. Vrin, especialmente pp. 31-84.

9 Sobre la tradición, cfr. L. DuCH (1999) Simbolisme i salut. Antropologia de la vida quotidiana, Montserrat, Publicacions de l'Abadia, 133-141, y L. Duch (2007) Un extraño en nuestra casa, Barcelona, Herder, vol. 1, 143-156. 
gado, a una herencia que pasa de padres a hijos según un acuerdo o un contrato entre dos o más partes. El segundo verbo significa el mismo acto de la transmisión o de la donación hecha por los sujetos. Por tanto hay que tener bien presente que la tradición supone algo (conocimiento, costumbre, ritual) que se traspasa, se da, que por supuesto debe incluir el mismo acto humano de la transmisión, la entrega. Toda tradición que no sea un mero tradicionalismo integra algo pasivo, que viene del pretérito, con la capacidad activa, receptora y recreadora del ser humano, que siempre ha de hacer frente a determinados retos históricos e interrogantes ineludibles. La presencia del pasado que implica la tradición, se recrea constantemente en el contexto pertinente del presente, tanto si aquél se afirma como si, por el contrario, se rechaza. En el proceso de la transmisión, la tradición, a pesar de las afirmaciones de quienes sostienen que se mantiene inamovible y constante, experimenta cambios formales, funcionales y de contenido, que se basan en la acomodación de la tradición a unas situaciones siempre nuevas, a los desafíos que son inherentes al hecho de vivir y convivir $y$, por qué no decirlo, a los intereses legítimos e ilegítimos del "establishment" de turno. ${ }^{10}$ Según Jürgen Habermas, la libertad que se debería mostrar en las relaciones con la tradición tiene su origen en la reflexión permanente (crítica). Esta circunstancia no invalida el hecho de que el hombre nazca y crezca en medio de una red de sistemas sociales que han sido configurados por numerosas tradiciones, que a menudo no son -o se pretende que no lo sean- conciliables entre sí.

Desde todos los puntos de vista, fisiológico, cultural, social, político, religioso, el hombre es un ser tradicional. La cuestión fundamental que continuamente se plantea se refiere al buen o mal uso de la tradición (o de las tradiciones). Como hemos afirmado con anterioridad, el buen uso implica siempre recreación, contextualización, sabiduría para moverse creativamente entre persistencia y cambio. El mal uso, sin embargo, da lugar a todo tipo de procesos de fundamentalismo religioso, social y políitico, que, como es sobradamente conocido, consiste en una peligrosa mezcla de un máximo de arcaísmo con un máximo de modernidad tecnológica. Hay que tener muy en cuenta que las corrientes religiosas y políticas con rasgos fundamentalistas manejan con mucha eficacia los avances tecnológicos de cada momento.

Habitualmente, se considera que el fundamento de la tradición viene dado por dos datos antropológicos: la mortalidad del hombre y el conjunto de actividades

\footnotetext{
${ }^{10}$ A pesar de sus innegables unilateralidades, el volumen editado por E. J. HOBSBAWN Y T. RANGER (1988) L'invent de la tradició, Vic, Eumo, ofrece una buena panorámica de los intereses creados que existen detrás de numerosas tradiciones europeas. Hay traducción castellana del original inglés, Barcelona 2002, Crítica.
} 
y de misiones que debe llevar a cabo cada generación. La tradición, al menos teóricamente, evita que cada ser humano y cada sociedad concreta tengan que repetir desde el comienzo el planteamiento de las cuestiones, que afectan a la plasmación de la existencia humana, y sus posibles soluciones de acuerdo con las diversas variables que en cada momento intervienen. La tradición es, fundamentalmente, estructura en la diacronía, jerarquización interna de los datos de la historia y de la cultura.

Obviamente, la tradición se encuentra íntimamente vinculada con la pedagogía. El ser humano, debido a sus acusadas limitaciones naturales, es el aprendiz por excelencia, que constantemente se ve impelido a actualizar, a "poner al día», la historia de la especie. Esta reactualización es un proceso pedagógico, que hace presente el pasado, adaptándolo y corrigiéndolo, de acuerdo con las necesidades, los deseos y las previsiones de la hora actual. Cada grupo humano posee su propia tradición cultural y participa de una manera más o menos directa en los bienes culturales de los grupos vecinos. Este hecho supone una cierta selección y elección de un fragmento de la gran tradición humana, porque, dada la finitud que le es congénita, ninguna sociedad humana puede, ni podrá, disponer de todas las posibilidades culturales (Shils). Cabe señalar que, quizás por primera vez en la historia, en nuestros días, está haciendo acto de presencia una cultura planetaria, que se presenta como planetaria y que, en realidad, no es sino una occidentalización de las tradiciones culturales de los otros pueblos. El problema que hoy se plantea es si el hombre, ser concreto y finito, que progresa, cuando lo hace, de lo particular a lo general, puede realizar su humanidad en el seno de una cultura sin rostro humano, es decir, sin los rasgos concretos y familiares de su cultura, de una cultura determinada.

Debido a una comprensión esencialista de la identidad y de la tradición, un malentendido muy frecuente -creemos que se detecta muy nítidamente en el texto episcopal- consiste en creer que la tradición religiosa y/o política ha sufrido a lo largo de los años una especie de degradación, de peligroso alejamiento respecto a unos orígenes, considerados perfectos y que, por ello mismo, se presentan, al margen de las especificaciones temporales y espaciales de individuos y colectividades, como paradigmáticos para toda la posterioridad. Se trata de la conocida teoría de la caída ("Verfallstheorie") de la historiografía romántica alemana. La solución que entonces se suele proponer a la supuesta situación de declive y pérdida de orientación es el regreso "ad fontes", la recuperación en el presente de unos orígenes y de una verdad intemporal que se atribuye a estas "fuentes", una recuperación arqueológica desde nuestro punto de vista, imposible y retórica. El gran cristiano que fue Søren Kierkegaard planteaba la siguiente alternativa que, 
según creemos, resume muy bien toda esta problemática: ¿̇somos nosotros los contemporáneos de Cristo o bien es Cristo nuestro contemporáneo? Él -y nosotros con él-se decantaba decididamente por la segunda posición: hoy y siempre, Cristo es nuestro contemporáneo. ${ }^{11}$

Desde una perspectiva antropológica, el aludido escrito episcopal muestra un cierto pesimismo antropológico, muy consecuente con los planteamientos que se hacen en el mismo. Este pesimismo se suele designar con el nombre de primitivismo antropológico, caracterizado por ofrecer una imagen idealizada y nostálgica de la sociedad primitiva y del hombre primitivo, que contrasta fuertemente con la negatividad en la imagen de la sociedad presente. ${ }^{12}$

Estas sencillas reflexiones de carácter antropológico no tiene otra intención que poner de relieve algunas posibilidades y algunos límites del texto episcopal.

${ }^{11}$ Cfr. L. Duch (2001) Jesucrist, el nostre contemporani, Montserrat, Publicacions de l'Abadia, especialmente pp. 9-29, en las que me refiero con cierto detalle a la posición de Kierkegaard.

12 Sobre el primitivismo antropológico, cfr. el importante estudio de W. Y. AdAMS (2003) Las raíces filosóficas de la antropología, Madrid, Trotta, 91-128. 